\title{
Coping with the violent patient in accident and emergency
}

\author{
Sylvia Winterbottom Casualty Department, Bolton Royal Infirmary, Bolton
}

\section{Editor's note}

This is another of the papers presented at the conference on 'Violence' organised under the auspices of the London Medical Group. Sylvia Winterbottom, who is based in the Casualty Department of Bolton Royal Infirmary, relates her experiences with various types of violent patients she meets daily in her work. She feels that many factors are to blame for the ever increasing violence but is more immediately concerned with how medical staff can prevent these outbursts. The guidance given in DHSS circulars seems to her totally inadequate and in some cases potentially dangerous. Ms Winterbottom concludes on a rather despairing note-she sees the current situation as one with little hope for the future.

Boy knifed to death on an errand. Baby's bedroom of horror. Punch-up after Youth Club. Door smashed in row at Police Station. Soccer Violence.

These headlines and others like them are unfortunately all too familiar in our daily newspapers. Each night at least one programme on television is dedicated to violence. If one wishes to spend an evening at the cinema the choice of subject is usually between sex and violence. The victims of these acts of violence about which we read invariably arrive at hospital Accident and Emergency units for treatment thus involving us all with their many problems.

Social violence today is on the increase in all its forms. Society appears to have accepted that violence is inevitable in day to day living. Whether this is a result of the increased publicity of violence and violent acts by all branches of the media or a symptom of modern stress is of little importance. What is of importance is the effect of this increase on the already strained resources of the Health Service.

The breakdown of social patterns within the family group has led in general to a lessening of social awareness and an increase of social apathy. One may take the ever increasing rate of vandalism prevalent among the younger age group as a symptom of this disease. It is, however, when this aggression is directed towards members of society that the resulting injuries require the services of the Health Care Team.

Whatever causes of violence there may be, and there are many theories put forward on this, it must be remembered that violence occurs, in varying degrees and forms each presenting its own differing, though related, problems in provision of care and management.

We in the Health Care team try to provide a healing and caring service for all patients, but in our modern society we are now forced to also provide a preventative one.

All the disciplines gathered here must be agreed that prevention of the violent outburst be the first consideration of everyone, because, unfortunately staff in general hospitals are inadequately equipped to accommodate this destructive element which now all too often is disrupting a hitherto effective service.

Are we in danger from violent patients? The answer must be 'yes'. By the very nature of our chosen work we daily witness the ever increasing evidence of man's inhumanity to man, intolerence and indeed contempt toward authority. Wonderful examples of these are to be seen every working day in Acciden and Emergency units throughout the country.

The Department of Health and Social Security circular of $1976 \mathrm{H} \mathrm{C}(76)$ I I on management of $\stackrel{\mathbb{Q}}{\Omega}$ violent or potentially violent hospital patients is, in $\overrightarrow{\overrightarrow{0}}$ my opinion, totally inadequate and irresponsible in 3 many aspects. It is of no use whatsoever to the people who encounter unpredictable violence. I wonder if the person who gave the advice under the heading 'How to handle patients suspected of $\overparen{\varnothing}$ possessing offensive weapons' would follow it. It $\frac{}{3}$ does not require much imagination to think what may happen if you approached a violent subject and asked him to hand over his weapon. How tragic it might be if a learner having read the circular and 옥 having taken it as a tried and tested guide line $D$ were then to follow the instruction.

May I continue on the circular a little longer because I feel very strongly about the nonchalant way in which the protection or should I say non- N protection of hospital personnel is being treated ? Part 2 item 18, reads:

Violence must always be dealt with promptly and positively. Staff are entitled to receive appropriate $\mathscr{\mathbb { D }}$ training and to expect that their actions will be : judged with understanding by their supervisors and by the Health Authority. This in no way means that an authority should condone or seek to defend actions it judges to be wrong or inappropriate, for 
example needless violence. It does mean that no blame should be attached to a member of staff who has acted in good faith and consistently with the training he has received.

If such a training exists outside the psychiatric hospitals I certainly have no knowledge of it and I know that my colleagues are also unaware of it.

The only training in dealing with the violent episode is in the psychiatric field and I have been assured on very good authority that incidents of violence within the psychiatric units are relatively rare owing to the interception of trained personnel, who, because of their special training are able to anticipate potential violence and therefore avoid its occurrence.

These points must surely prove that the most vulnerable areas, for example, casualty, out-patient departments and general wards, where the unexpected is likely to happen, and which are covered by staff who have not had the necessary training in coping with the violent episode, have a desperate and urgent need for specialised training.

It is beyond my comprehension how anyone can judge someone who has dealt with a violent outburst, to the best of his ability, when he was not even present.

At the Confederation of Health Service Employees' annual conference, president Mr Eric Wilson made a valid point when he stated 'While Health Authorities were willing to offer sympathy to the victims of attack they have been slow to take action to protect their staff from violence in the first place.'

It makes one wonder for how much longer medical and nursing personnel will be expected to cope with the violent episode plus all the other aggravations being experienced at the present moment and at the same time maintain the high standards required in all our other duties. Is it fair to continue to expect us to cope with these very dangerous situations with in many cases no help at all?

Unfortunately, as elsewhere, aggression and violence is increasing within the Accident and Emergency Department. Public attitudes towards hospital personnel are changing constantly and open hostility to staff is becoming more apparent. I would like to talk about some of the categories we encounter in Accident and Emergency and how we deal with them.

\section{Crowd violence}

Obviously fighting between patients within the unit is to be avoided at all costs. However, the management and prevention of this may become difficult, if, for instance large numbers of opposing factions e.g. opposing football team supporters are being admitted at the same time. Adequate segregation is required but in most Accident and Emergency departments this is impossible.
Saturdays during the football season can prove to be a headache most weeks when the team's supporters arrive. We are very unfortunate in our town to have a phantom brick thrower at the local football ground who provides us with a great deal of work before kick off. On arrival in casualty these people are often responsible for disrupting the work already in progress. If, for instance, their injuries are only minor they have to wait their turn along with other non-urgent cases. This can lead to instant aggression as their only concern is to get back to the match. Unfortunately it usually ends up with a call for police assistance as they will not listen to any kind of explanation.

Even more difficult to cope with is the football fan who is escorted to hospital, along with several friends, in a more serious condition after a skirmish at the ground. While waiting for their companion to be dealt with the friends can cause chaos on the department, asking continually 'what's going on,' demanding to speak to the doctor, making a general nuisance of themselves, and if a supporter of the opposite team happens to come in requiring our help the situation can get out of hand and police assistance is required.

\section{The verbally agressive patient}

This type of patient brings many problems, the ç most serious being a total communication barrier. He comes into the department ready to do battle and quite often succeeds in causing his own war. It is very difficult to keep control over your own feelings while at the same time trying to get co-operation from your patient, but without it the results could prove fatal.

A male ambulant patient was brought to Accident and Emergency with a history of chest pains of at least fifteen days duration. On admission the man was symptom free. The usual observations were done and found to be within normal limits. After examination by the doctor, who found nothing of significance, the patient dressed himself. $\mathrm{He}$ was $\delta$ given a prescription for analgesics and told he could $₹$ go home under the care of his own doctor if he felt a 을 visit necessary. At this point the patient demanded ambulance transport home. As there was no clinical indication that this was necessary it was refused, whereupon the patient became extremely aggressive G and threatened legal action. The offer to obtain a $N$ taxi was also refused, the patient demanding his $\underset{\mathrm{N}}{\mathrm{N}}$ rights to ambulance transport. The man demanded 0 to see the doctor who also explained that hospital transport was unnecessary. There followed a $\frac{\mathscr{D}}{\mathscr{C}}$ torrent of abuse towards the medical and nursing $\stackrel{\oplus}{\rightarrow}$ staff and the man stormed from the department, 0 only to be returned a short time later as a corpse. He had suffered a massive myocardial infarction at $\stackrel{\Omega}{\overparen{D}}$ the bus stop.

Frustration, fear and anger are often causes of $\frac{\square}{0}$ 
aggression and violence. Understanding of these factors may prevent deterioration of a situation.

Frustration-Possibly due to waiting for attention (unfortunate but inevitable) may be allayed by a few thoughtful words.

Fear-May be eased by an explanation and a kind understanding attitude.

Anger-May be due to a variety of reasonable or imaginary complaints or poor communication may be the cause, and it must be handled in a kind but very firm manner.

I am not saying that tact and sympathy are the ultimate answer to the problem of violence within the Accident Unit. A variety of methods must be employed. Often a simple chat with an understanding person is the answer and reasoning with a patient may prevent further acts of aggression; this is presupposing that the patient has sufficient insight to be able to reason, not always the case after drink, drug abuse or in psychiatric illness. Here firm but gentle restraint and sedation may be the only solution.

In the case of the frustrated or angry patient, one may not always have time due to pressure of other more urgent work, road accidents etc, to spend explaining to these people and this is when the incident is in danger of escalating out of control.

We are all agreed that prevention of the violent outburst should be the first objective of everyone and it is at this point that I would ask us all to look at our own attitudes. We are in the ideal situation to trigger a violent outburst, just the wrong look at the wrong moment will achieve this.

I think at this stage it is worth mentioning that a great deal of the anger and aggression received by us is directed, not by the patient, but by his relatives or friends, and this makes it doubly difficult to cope with because you cannot be sure whether their attitude is due to the circumstances of their relative or whether they are just being obstinate.

A gentleman (I use the term loosely) who escorted his injured friend to casualty in the early hours proved to be more of a problem than the patient. Following the patient's admission with a severely lacerated hand the friend then decided that he also needed medical attention stating that he had injured his arm. This was agreed to and the doctor was once more sent for. After examination the doctor ordered a sling and told the patient to return for $\mathrm{X}$-ray at 9 o'clock, whereupon $\mathrm{Mr} \mathrm{X}$ demanded an immediate $\mathrm{X}$-ray. This was refused and a rowdy argument followed. The doctor then left the department. $\mathrm{Mr} \mathrm{X}$ shouting and abusing went into the reception area and threw a wooden box over the desk at the staff-nurse who immediately rang for police assistance. On hearing the nurse's request $\mathrm{Mr}$ $X$ left the department and staff-nurse informed the police that they would not be required. Simultaneously, an ambulance arrived bringing two more patients whose driver stated that $\mathrm{Mr} \mathrm{X}$ was causing a disturbance at the door. The police were recalled. $\frac{}{m}$ After delivering his patients the ambulanceman ${ }_{5}$ went outside to observe $\mathrm{Mr} \mathrm{X}$, only to discover his

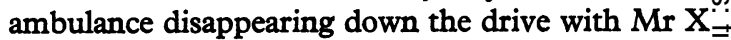
in control. The ambulance was found abandoned some time later.

Other types of violence encountered on Accident and Emergency are from head injuries, the post- $\frac{\bar{p}}{\sqrt{6}}$ epileptic state and hypoglycaemia. These patients as $\stackrel{\varnothing}{\varnothing}$ we all know, can become extremely agitated and areo very often responsible for injuring the staff uninten- tionally. However, one usually finds in the case of. epileptics and diabetics that the first thing they do $\vec{\omega}$ after treatment and return to rational behaviour iso apologise profusely for any inconvenience caused. Most people with head injuries are completely obli- - o vious of the the fact that they have caused anyw disturbance.

\section{Familial violence}

This type of violence is perhaps one of the most $\mathbb{C}$ distressing to deal with regardless of what form it takes. We have many wives who visit us on a 3 regular basis after being physically assaulted by their husbands. A great deal of tact and sympathy is needed when dealing with this kind of violence. In these cases only the people concerned can decide. what to do for the best. Many things have to beO considered by the unfortunate victim. When thes necessary treatment has been given we can suggest $\frac{}{0}$ that a chat with an understanding social worker mayo help and in many cases it does.

Granny bashing does happen in some homes and $\overrightarrow{\vec{O}}$ we have to be on the alert for it when old people are 3 brought to hospital with unexplained bumps and bruises. These elderly citizens are in the unenviable position of not being able to complain, due to the fact that they are totally reliant upon the people responsible for their homes, food etc. If there areo any grounds for suspicion these cases, if sent home, must be followed up by the social workers who cano very often relieve some of the strain by suggesting granny goes to a home for the elderly a couple of $\bigcirc$ days a week, thus giving both parties a very necessary $D$ break.

The most obnoxious type of familial violence that we come in contact with is the non-accidental ${ }^{-5}$ injury to children. Defenceless children are used ${ }^{N}$ by their own parents for a variety of reasons as $N$ human punch bags. We must always be on the alerto for these children and permanent staff on Accidento and Emergency units are in the front line in recognition of this problem.

One cannot overstress the importance of being on 7 guard for these children at all times because if the 0 battered child is left to be reared in this dangerously $\cong$ violent atmosphere is in danger of becoming $a \stackrel{\mathbb{Q}}{D}$ battering parent. 


\section{Self-inflicted violence}

Most hospitals in this country today who provide a twenty-four-hour service for Accidents and Emergencies find themselves with a list of regular visitors. These are the people who in one form or another inflict violence on their own bodies. A variety of methods are employed to inflict harm from the more popular overdosing and wrist slashing we go on to severe burning, swallowing of glass, swallowing thermometers, driving nails into their heads, and of course, the frequently present drug addict who has been mainlining for some time and comes to us with infected lesions all over his body. These people on the whole are more to be pitied than scorned.

How can we help these poor unfortunate beings who very often disrupt the whole department with the performance they give if they are inebriated or under the influence of drugs? We can only give the necessary treatment regarding their injuries and then refer them to the psychiatrist. But what do we do when the psychiatrists do not want to know? Who are we to blame them when they have tried so many times with a patient and had no success, as in the following case: David is one of the most lovable, but yet frustrating human beings who visits us on a regular basis. We always know when he has arrived because he is constantly calling, in a very strong Scottish accent, for God and his psychiatrist. $\mathrm{He}$ is always drunk, usually due to a large consumption of sherry. If lifted above floor level he will most certainly throw himself off the chair or stretcher on to which he has been put. David has inflicted violence onto himself in several ways over several years. His front, from chin to umbilicus is all scar tissue as are his arms from shoulder to finger ends. He has overdosed on numerous occasions, burned himself and in a violent outburst cut his own throat and his wife's. David is forty years old and has been visiting us for several years. Now when he comes we have no help to offer because no one wants to know. David's cry for help is only one that we turn away, but there are many more like him.

Manchester's Chief Constable $\mathrm{Mr}$ James Anderton, stated in his annual report in 1978, 'Crime, public disorder, violence and vandalism are like bursting boils on the skin of life. It cannot be $A$ unreasonable to hope for a society in which good 웅 sense, courtesy, respect and kindness predominate again.'

While agreeing with $\mathrm{Mr}$ Anderton that it is not unreasonable to hope for a peaceful suciety I feel, as a worker in a caring profession, who observes violence every day in varying forms, grave despair - we are rapidly reaching the point of no return 